\title{
CORRIGENDUM
}

\section{A new look at dietary carbohydrate: chemistry, physiology and health}

JH Cummings, MB Roberfroid, H Andersson, C Barth, A Ferro-Luzzi, Y Ghoos, M Gibney, K Hermansen, WPT James, O Korver, D Lairon, G Pascal and AGS Voragen, members of the Paris Carbohydrate Group

European Journal of Clinical Nutrition (2010) 64, 334; doi:10.1038/ejcn.2010.10

Correction to: European Journal of Clinical Nutrition (1997) 51, 417-423; doi:10.1038/sj.ejcn.1600427

Since the publication of this paper, the authors have noticed that one of the author names was incorrectly listed as $\mathrm{K}$ Hermonsen. The correct name is shown above.

The authors apologize for any inconvenience caused. 